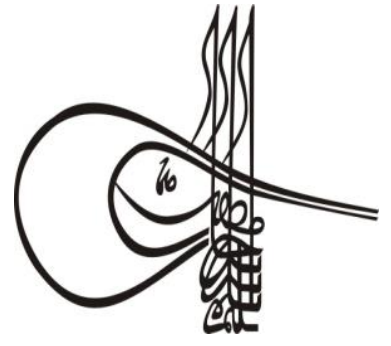

Received/Geliş: 10.04.2019

ar Report Dates/Rapor Tarihleri: Referee 1 (29.04.2019)-Referee 2 (04.05.2019)

\section{Turkigh Studies Educational Sciences}

Volume 14 Issue 3, 2019, p. 681-697

DOI: 10.29228/TurkishStudies.22903

ISSN: 2667-5609

Skopje/MACEDONIA-Ankara/TURKEY

Research Article / Araştırma Makalesi

Article Info/Makale Bilgisi

This article was checked by turnitin.

\title{
GÜNCEL YAKLAŞIMLAR ÇERÇEVESİNDE MÜZİKSEL YARATICILIK VE DEĞERLENDİRİLMESİ
}

\author{
Adem $M A B A^{*}$
}

\section{öz}

Günümüzde oldukça sık duymaya başladığımız yaratıcılık terimi, uzun yıllar üzerine çalışılan ve araştırmalar yapılan bir konu olmuştur. Yaratıcılık, sanatta olduğu kadar, bilim, teknoloji ve daha diğer birçok alanda da programların vazgeçilmez bir parçasıdır. Yaratıcılık ile ilgili çalışmalar incelediğinde, yaratıcılığın Platon'a kadar uzanan, birçok din ve toplumun da ilgisini çeken bir konu olduğu görülmektedir. Özellikle II. Dünya Savaşından sonra askeri savunma sistemleri, uzay bilimleri ve mühendislik gibi alanlarda oldukça hızlı ilerlemeler kaydedilmeye başlanmıştır. Bu ilerlemeler yaratıcı düşüncenin geliştirilmesi ve kullanılmasıyla mümkün olmuştur. Hızla gelişmekte ve değişmekte olan çağı yakalayabilmek için, her alanda yaratıcı fikirler ve ürünler ortaya koymak bir gereklilik haline gelmiştir. Son yıllarda, eğitim programları incelendiğinde yaratıcılık ile ilgili birçok kazanıma yer verildiği ve yaratıcı etkinliklerin tasarlandığı görülmektedir. Çocuklarda yaratıcılığın eğitim yoluyla geliştirilmesi, gelecekte ülkemizin bilim, sanat, spor ve teknoloji gibi alanlarda ilerlemesi ve bu gibi alanlarda çığır açabilecek bireylerin yetiştirilmesine katkı sağlayacaktır. Yaratıcılık ile ilgili geçmiște yapılmış ve hali hazırda yapılmakta olan bilimsel çalışmaların incelenip ülkemiz öğretim programlarına kazandırılması, çocukların üst düzey düşünme berilerini geliştirerek daha üretken ve yenilikçi olmalarını sağlayacaktır. Bu çalışmada yaratıcılık, müziksel yaratıcılık, müziksel yaratıcılığın gelişim süreci ve son y1llarda müziksel yaratıcılığı değerlendirmeye yönelik geliştirilen ölçme araçlarının kullanımına ilişkin detaylı bilgiye ve güncel araştırmalara yer verilmiștir.

Anahtar Kelimeler: Yaratıcılık, müziksel yaratıc1lı, rubrik. 


\title{
MUSICAL CREATIVITY AND EVALUATION IN THE FRAMEWORK OF CURRENT APPROACHES
}

\begin{abstract}
The term creativity, which we started to hear quite often, has been a subject that has been studied and researched for many years. Creativity is an indispensable part of programs in science, technology and many other fields as well as in art. When studies on creativity are examined, it is seen that creativity is a subject that extends to Plato and attracts the attention of many religions and societies. Especially after World War II, rapid advances were made in the fields of military defense systems, space sciences and engineering. These advances have been possible through the development and use of creative thinking. In order to catch up with the rapidly developing and changing age, it has become a necessity to create creative ideas and products in every field. In recent years, when the educational programs are examined, it has been seen that there are many gains related to creativity and creative activities are designed. The development of creativity in children through education will contribute to the progress of our country in the fields of science, art, sports and technology and to raise individuals who can break new ground in such fields. By examining the scientific studies that have been done about creativity in the past and currently being carried out in our country's curricula, it will enable children to be more productive and innovative by developing their high-level thinking. When education programs are examined in recent years, it has been seen that there are many achievements related to creativity and creative activities are designed. In this study, detailed information and current studies are included about creativity, musical creativity, the development process of musical creativity and the use of tools to evaluate musical creativity in recent years.
\end{abstract}

\section{STRUCTURED ABSTRACT}

When studies on creativity are examined, it is seen that creativity is a subject that extends to Plato and attracts the attention of many religions and societies. Especially after World War II, rapid advances were made in the fields of military defense systems, aerospace and engineering. These advances have been possible through the development and use of creative thinking (Shaheen, 2010). As a result, many developed and developing countries including the USA and the UK, have increased their studies on creativity and education and started to see creativity as the main purpose of education (Rawat, Qazi, $\&$ Hamid, 2012; Shaheen, 2012). 2010). The aim of the new curricula prepared in this direction is to give students the opportunity to be creative, innovative and entrepreneurial by developing their critical thinking, creative thinking and problem solving skills and making them more rational for the problem situations they face (Shaheen, 2010).

Torrance (1966), defines creativity as a process of being sensitive to problems, lack of knowledge, incomplete elements and incompatibilities and having results by identifying difficulties, finding solutions, making predictions or formulating hypotheses about

Turkish Studies - Educational Sciences

Volume 14 Issue 3, 2019 
deficiencies, testing and re-testing these hypotheses and possibly testing them and retesting results.

Csikszentmihalyi (1999), divides creative people into three categories: bright, creative on personal level and unlimited creative. According to Csikszentmihalyi (1999), the people who have brilliant intelligence and can create extraordinary ideas are described as bright. The people who have authentic, original, sensible ideas and are not known by the people even if their creativity is high are defined as creative on personal level. The people who change the structure of society and do pioneer work over time are described unlimited creative. Based on all these definitions, Sak (2014) defined creativity as creating a new and suitable product.

Although studies on creativity seem to be recent, studies on musical creativity date back to 1931 (Mazzola, Park \& Thalmann, 2011:146). Musical creativity, which is one of the genres of creativity, is the capacity to produce new, original ideas and products related to music (Piji, 2003; Swanwick \& Tilmann, 1986). According to Webster (2002), musical creativity is that the mind is in an active and structured sound thinking process in order to produce products that are new to the creator of music.

The evaluation of musical creativity has been an important topic in the music world for many years. Researchers have conducted various studies (Vaughan, 1971; Gorder, 1976; Webster, 1979; Webster, 1983; Hickey, 1999) to measure musical creativity of students from different age levels.

In recent years, it has been seen that innovations in education and training fields have increased rapidly as in all other fields. In particular, instead of teacher-oriented teaching programs, more learner and process-oriented programs have started to be used. In the light of these developments, there have been changes in measurement and evaluation methods. Product-oriented assessment methods, which are commonly used before, have been replaced by process and performance-oriented evaluations (Abal1, Öztürk \& Şahin, 2014). In performance-oriented assessment methods, cognitive, affective, psychomotor and social skills of students are dealt and examined in different dimensions. Performance-oriented evaluation method helps to measure learning goals and behaviours which cannot be measured through classical measurement tools, to increase the permanence of learning and students motivation and to make teachers more active in the measurement process (Abalı Öztürk \& Şahin, 2014; Birel \& Albuz, 2014; Öztürk \& Güdek, 2016).

When the literature is reviewed, it indicated that creativity and musical creativity are concepts that have been studied by many researchers in recent years. It also showed that the studies focused on defining, measuring, developing and evaluating creativity.

When the studies (Csikszentmihalyi, 1999; Gardner, 2011; Guilford, 1950; Kurtzberg \& Amabile, 2001; Torrance, 1962; 1966; 1974; Sternberg, 2006) on defining creativity were examined, in general terms, creativity has been defined a new and suitable product. In addition to this definition, the studies revealed that creativity consists of intellectual skills, knowledge, thinking styles, personality, motivation 
and contextual variables (Sternberg \& Lubart, 1991; 1995). It has also been reported that creativity includes fluency, flexibility, innovation, synthesis, analysis, rearrangement, redefinition, complexity and detailing structures (Kurtzberg \& Amabile, 2001).

Similarly, many researchers (Elliott, 1989; Hickey \& Webster, 2001; Piji, 2003; Swanwick \& Tilmann, 1986; Webster, 1988; 2002) attempted to describe musical creativity, which is a branch of creativity, as producing a new and suitable idea or product in musical sense. In the process of producing creative product in the musical sense, individuals primarily have a purpose and use their thinking skills in the composition, performance and analysis processes which are developed for this purpose. As in the divergent thinking process, in the line with predisposition and opportunities making creative product activating skills consist of preparation, incubation, enlightenment and proof processes. In the convergent thinking process, the same creative product making process takes place in line with the variables of aesthetic sensitivity, conceptual understanding and mastery. These processes interact completely with each other. At the end of these processes, the creative product emerges as a composition (composition, work), performance or analysis. At the same time, it has been seen that musical development is an important factor in the development of musical creativity. In parallel with cognitive development, this development has been seen to take place in a sensory way in the first years of life and afterwards through imitation, play and meta-cognitive learning respectively.

When studies having been conducted to measure and evaluate musical creativity indicated that creative thinking tests in music are based on Torrance's Creative Thinking Tests. These tests are designed as a performance evaluation process.

Holistic Rubrics began to be used since researchers have started to prefer process oriented evaluation methods rather than product oriented evaluation of creativity in music. This evaluation method also contributes to measuring musical creativity, objectives and behaviours, increasing the retention of learning and student motivation, and educators' being active in the measurement process.

Keywords: Creativity, musical creativity, rubric.

\section{Giriş}

\section{Yaraticilık}

Yaratıcılık ile ilgili çalışmalar incelediğinde, yaratıcılı̆̆ın Platon'a kadar uzanan, birç̧ok din ve toplumun da ilgisini çeken bir konu olduğu görülmektedir. Özellikle II. Dünya Savaşından sonra askeri savunma sistemleri, uzaycılık ve mühendislik gibi alanlarda oldukça hızlı ilerlemeler kaydedilmeye başlanmıştır. $\mathrm{Bu}$ ilerlemeler yaratıcı düşüncenin geliştirilmesi ve kullanılmasıyla mümkün olmuştur (Shaheen, 2010). Bunun sonucu olarak, son yıllarda ABD ve İngiltere gibi ülkeler başta olmak üzere diğer birçok gelişmiş ve gelişmekte olan ülkeler de, yaratıcılık konusu ve eğitimi üzerine çalışmalarını arttırmış, yaratıcılığı eğitimin esas amacı olarak görmeğe başlamışlardır (Rawat, Qazi, \& Hamid, 2012; Shaheen, 2010). Bu doğrultuda hazırlanan yeni öğretim programlarının amacı, öğrencilerin eleştirel düşünme, yaratıcı düşünme ve problem çözme becerilerini geliştirerek ve 
karşılaştıkları problem durumlarına yönelik daha akılcı olmalarını sağlayan, yaratıcı, yenilikçi ve girişimci olma firsatı vermektir (Shaheen, 2010).

Bugün var olan yaratıcılık alanı, büyük ölçüde J. P. Guilford (1950) ve E. Paul Torrance'nin $(1962,1974)$ öncü çalışmaları sonucunda ortaya çıkmıştır. Yaratıcılığın doğası ve bunu ölçmenin yolları üzerine Guilford ve Torrance'ın ortaya koydukları kuramlarda oldukça fazla ortak nokta bulunmaktadır. Her iki bilim insanı da temelde psikometrik teorisyenler olmaları nedeniyle ve yaratıcılı̆̆ 1 psikometrik bir bakış açısıyla ölçmeye çalışmıştır (Sternberg, 2006). J. P. Guilford'un 1950'deki Amerikan Psikologlar Birliği'ndeki çalışmaları, günümüzde gelişen yaratıcılık araștırmalarına ilham vermiștir. Guilford'un, alana en büyük katkısı farklı yapılara göre belirsiz ancak ilginç olan bireysel yaratıcı düşünceyi tanımlayan yaratıcılık kavramını belirlemesidir. Yaratıcıllı̆ın akıcılık, esneklik, yenilik, sentez, analiz, yeniden düzenleme ve yeniden tanımlamayı, karmaşıklığı ve detaylandırmayı içeren yapılardan oluştuğunu ortaya koymuştur (Kurtzberg \& Amabile, 2001). Guilford, yaratıcılığın tüm insanlarda sürekli bir özellik olduğunu ve yaratıcı yeteneği olan bireylerin "hepimizin sahip olduğu şeylerden daha fazlasına" sahip olduğunu savunmuştur (Guilford, 1950, s. 446). Her kurucu katkıda olduğu gibi, Guilford'un yaratıcı bireyin özelliklerine, motivasyonlarına ve davranışlarına odaklanma tercihi, yaratııılığın on yıllardır kavramsallaştırılmasının yolunu açmıştır (Kurtzberg \& Amabile, 2001).

Torrance (1966), ise yaratıcılığı problemlere, bilgi eksikliklerine, eksik unsurlara ve uyumsuzluklara karşı duyarlı olma süreci, zorlukları belirleme, çözüm bulma, tahminler yapma veya eksikliklerle ilgili hipotezler formüle etme, bu hipotezleri test etme ve yeniden test etme ve muhtemelen bunları değiştirerek test etme ve yeniden test ederek sonuç elde etme olarak tanımlamıştır.

Csikszentmihalyi (1999), yaratıcı kişileri; parlak, kişisel düzeyde yaratıcı ve sınırsız yaratıcı olmak üzere üç gruba ayırmıştır. Csikszentmihalyi (1999), genellikle kıvrak zekâya sahip, sıra dışı fikirler üretebilen bireyler için "parlak", özgün, orijinal ve mantıklı fikirlere sahip, yaratıcılıkları yüksek olmasına rağmen yaptıklarından başkalarının haberdar olmadığı bireyler için "kişisel düzeyde yaratıcı, toplumun yapısını değiştiren ve zaman içinde çığır açan çalışmalar yapabilen kişiler için de “ sınırsız yaratıcı" tanımlamalarını kullanmıştır. Einstein, Picasso ve Edison bu gruba giren kişilerden bazılarıdır (Csikszentmihalyi, 2014). Yaratıcılık üzerine yapılan araştırmalar incelendiğinde, yaratıcılık ile ilgili birçok çalışma, varsayım ve farklı tanımlamaların bulunduğu görülmektedir (Elliott, 1989; Ryan \& Brown, 2012). Wallas (1926), yaratıc1lıtaki zihinsel faaliyet sürecinin; hazırlık, kuluçka, aydınlama ve ispat olmak üzere toplam dört aşamadan oluştuğunu belirtmiştir. Gardner (2011), çalışmalarında yaratıcılığı iki temel gruba ayırmıştır. Birincisi yani küçük "c" ile ifade ettiği yaratıcılık tipi, hepimizin günlük hayatta kullandığ 1 , ikincisi yani büyük "C" olarak ifade edilen yaratıcılık türü ise, insanlık tarihinde çı̆̆ır açan ve nadiren görülen yaratıcılık şeklinde açıklamıştır (Craft, Gardner, \& Claxton, 2007). Yaratıcılığı yüksek olan bireylerin özellikleri incelendiğinde, meraklı, temel sorunlarla ilgilenen, özgür, enerjik ve espritüel bir yapıya sahip oldukları görülmektedir (Csikszentmihalyi, 1999).

Sternberg ve meslektaşları (Sternberg, Kaufman \& Pretz, 2002; Sternberg \& Lubart, 1995, 1996) yaratıcılığı tanımlarken bir birleşme yaklaşımı kullanmayı tercih etmiştir. Sternberg \& Lubart'ın (1991; 1995), yaratıc1lık teorisinde yaratıcılık; yaratıcı ve istekli kişilerin fikir dünyasında "ucuza alıp pahaliya satma" olarak tanımlanmaktadır. Ucuza satın almak, bilinmeyen veya lehine olmayan ancak büyüme potansiyeli olan fikirlerin peşinde koşmak anlamına gelmektedir. Genellikle, bu fikirler ilk sunulduğunda, başkaları tarafından dirençle karşılansa da yaratıcı bireyler bu direniş karşısında durarak, yeni veya popüler olmayan bir fikre doğru ilerler ve ürünlerini pahalıya satarlar. Bu teori, entelektüel beceriler, bilgi, düşünme stilleri, kişilik, motivasyon ve çevre olmak üzere birbiriyle ilişkili altı bileşenden oluşmaktadır. Bu kaynakların seviyeleri birbirinden farklı olmasına rağmen, kullanım 
sıklıkları tamamen bireysel farklılıklara göre değişkenlik göstermektedir (Sternberg \& Lubart, 1991; 1995).

Sternberg (1985), üç entelektüel becerinin yaratıcılıkta oldukça önemli olduğunu vurgulamıştır. Bunlar; a) problemleri yeni bakış açıları ile görme ve geleneksel düşüncenin sınırlarını aşma becerisi, b) hangi düşüncelerin peşinden gitmeye değer olup olmadığını anlamak için analitik düşünme becerisi ve c) fikirlerini pratikteki değerini anlama ve başkalarını ikna etme konusundaki bağlamsal becerilerdir. Sternberg (2006) bilginin, yaratıcılık üzerinde iki farklı etkisi olabileceğini belirtmiştir. Bir yandan, bir konuda ilerleme kaydedebilmek için yeterli bilgiye sahip olunması gerekirken, diğer yandan konu hakkındaki kapalı bilginin sağlam bir perspektife neden olması, dolayısıyla da kişinin geçmişte sorun gördüğü yolun ötesine geçememesine neden olabilmektedir. Yani bilgi yaratıcılığa yardımcı olabilir ya da yaratıcılığı engelleyebilir. Sternberg \& Lubart (1991; 1995), yaratıcılık için önemli kişilik özelliklerinin, engellerin üstesinden gelmek için istekli olma, mantıklı risk almak için istekli olma, belirsizliği tolere etmeye istekli olma ve öz-yeterlilik olduğunu belirtmiştir. Sternberg (2006), son olarak yaratıcı fikirlerin destekleyici ve ödüllendirici bir ortama ihtiyacı olduğunu belirtmiştir. Bir kişinin yaratıcı bir şekilde düşünmek için gereken tüm iç kaynaklara sahip olabileceğini, ancak bir miktar çevresel destek olmadan (bu fikirleri önermek için bir forum gibi), bir insanın kendi içinde sahip olduğu yaratıcılığı asla gösteremeyebileceğini vurgulamıştır. Sternberg (2006)'e göre, bu altı bileşenin birleşmesiyle ilgili olarak, yaratıcılığın, her bir bileşen için bir kişinin seviyesinin basit bir miktarından fazlasını içerdiği varsayılmaktadır. İlk olarak, diğer bileşenler üzerindeki seviyelere bakılmaksızın yaratıcılığın mümkün olmadığı bazı bileşenler (örneğin: bilgi) için eşikler olabilmektedir. İkincisi, bir bileşen (örneğin: motivasyon) üzerindeki bir gücün bir başka bileşen (örneğin: çevre) üzerindeki bir zayıflığı önlediği durumlarda kısmi telafi meydana gelebilmektedir. Üçüncüsü ise, zeka ve motivasyon bileşenlerinin yüksek olmasının, yaratıcıllı̆ı arttıracağıdır. Amabile (1983) tarafindan yapılan araştırmada, yaratıcı çalışma için motivasyonun önemi ortaya konmuştur. Bunun yanı sıra insanların yaptıkları işi sevmedikleri ve potansiyel ödüller yerine işe odaklandıkları sürece, bir alanda nadiren gerçekten yaratıcı çalışmalar yaptıklarını belirtmiştir. Sak, (2014) bütün bu tanımlardan yola çıkarak yaratıcılığı "yeni ve uygun bir ürün ortaya koyma" olarak tanımlamıştır.

\section{Çocukta Yaratıcılığı Geliştiren Etmenler}

Son yıllarda yapılan çalışmalar incelendiğinde yaratıcı düşünme becerisinin erken yaşlarda gelişmeye başlayarak yaş dönemlerine göre farklılık gösteren bir süreç olduğu belirtilmiştir (Amabile, 1983; Csikszentmihalyi, 1999; Kurtzberg \& Amabile, 2001; Sternberg \& Lubart, 1991; 1995; Wallas, 1926). Çocuklarda yaratıcılığı geliştirmek için algılarının zenginleştirilmesi, gözlem ve hafıza eğitimine gerekli önemin verilmesi, üretici düşünme yöntemlerinin kazandırılması, yeni biçimler aramaya, bulmaya ve bunları anlatıp yorumlamaya yöneltilmesi, sanatla ilgili faaliyetlere yönlendirilmesi, duygu ve düşüncelerini ifade edebilme alışkanlığı kazandırılması, pratik, çabuk, kararlı ve cesaretli olmalarına olanak tanınması, imgelerinin geliştirilmesine katkıda bulunulması, fiziki çevrelerinin (sınıf, atölye, koridor ) iyileştirilmesi, kendi kendilerine çalışıp, teknik yönden birikim ve doyum sağlayabilecekleri ortamların hazırlanması (kitaplık, atölye vb. yerlerden yararlanması gibi), sanatsal ve kültürel etkinlikleri izleyebilme olanaklarının yaratılması (müze, sergi, doğa, tarihi vs. gezileri) ve öğretilecek konuların, öğrencilerin çevresinden ve yaşamlarından seçilmesinin önemi vurgulanmıştır (Amabile, 1983; Csikszentmihalyi, 1999; Kurtzberg \& Amabile, 2001; Sternberg \& Lubart, 1991; 1995; Wallas, 1926).

Yaratıcı düşünme özgürdür, hareketlidir, üretken bir süreçtir. Çok yönlü bakmak, çok seçenekli çözüm yolları bulmak gerekir. Tasarımcı, yaratıcı eylem sürecidir, çevresini yaratma adına görmeli ve kullanmalı, tüm kaynaklardan yararlanmalıdır. Bu kaynaklar; doğal çevremiz, insan gereksinmeleri, istekleri, eğitilmiş insan gücü, sezgi, bilim, kültür, madde ve olanakları, teknoloji ve olanakları, insanın ürettiği her şey ve en önemlisi de sanattır. Yaratıcılığı yüksek olan bireylerin diğer 
özellikleri incelendiğinde, meraklı, temel sorunlarla ilgilenen, özgür düşüncelere sahip, enerjik ve espritüel oldukları görülmektedir (Amabile, 1983; Csikszentmihalyi, 1999).

\section{Müziksel Yaratıcılık}

Yaratıcılık üzerine yapılan çalışmalar her ne kadar yeni gibi görünse de, müziksel yaratıcılık ile ilgili çalışmalar 1931'e dayanmaktadır (Mazzola, Park \& Thalmann, 2011:146). Yaratıc1lk türlerinden biri olan müziksel yaratıc1lı, müzikle ilgili yeni, orijinal, düşünce ve ürünleri üretebilme kapasitesidir (Piji,2003; Swanwick \& Tilmann,1986). Webster (2002)'e göre müziksel yaratıcilık, müziği yaratan kişi için yeni olan ürünleri üretmek amacıyla aklın aktif ve yapılandırılmış bir ses düşünme süreci içerisinde olmasıdır. Webster (2002)'in modeline göre müzikte yaratıcı düşünme süreci; ürün amacı, düşünme süreci ve yaratıcı ürünler olmak üzere 3 aşamadan oluşmaktadır (Şekil $1)$.

Şekil 1. Webster Yaratıcı Düşünme Modeli

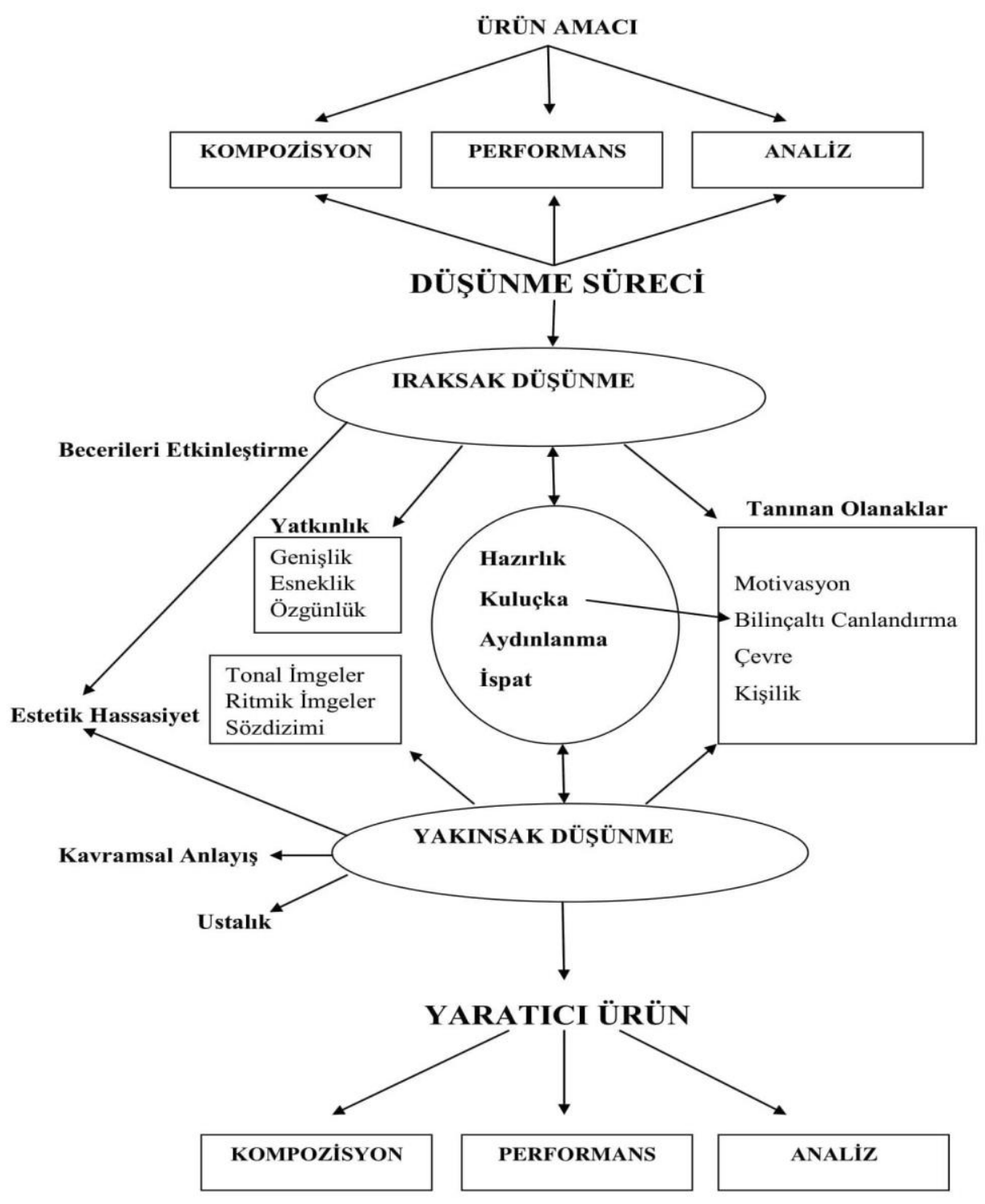

Turkish Studies - Educational Sciences

Volume 14 Issue 3, 2019 
Elliott, (1989) bu süreci; üretici, üretim aşaması ve ortaya çıkan yeni ürün olarak ele almış, bu süreçlerin tamamen iç içe ve birbirleriyle ilişkili olduğunu ileri sürmüştür. Burnard (2007)'a göre, müziksel yaratıcılık, farklı araçlar, teknolojiler, kurallar ve ritüel [gelenek] uygulamaları ile farklı bağlamlarda ortaya çıkmaktadır. Stenberg \& Lubart (1996)'a göre yaratıcılık yeni ve uygun bir ürün ortaya koyma yeteneği olarak tanımlamıştır. Buna ek olarak müziksel yaratıcılık, bir eser, kompozisyon veya doğaçlama, yorumlama, remiks, kayıt ya da prodüksiyon [yapım] gibi bir ürün ortaya koymak olarak tanımlanmıştır (Mazzola, Park, \& Thalmann, 2011:145). Swanwick \& Tillman (1986), çocuklardaki müziksel gelişim aşamalarının yaşa bağlı olarak nasıl bir sıra izlediğini 4 yıl süren bir çalışmada ortaya koymuşlardır (Şekil 2).

Şekil 2. Müziksel Gelişim Aşamaları (Swanwick \& Tilmann, 1986).

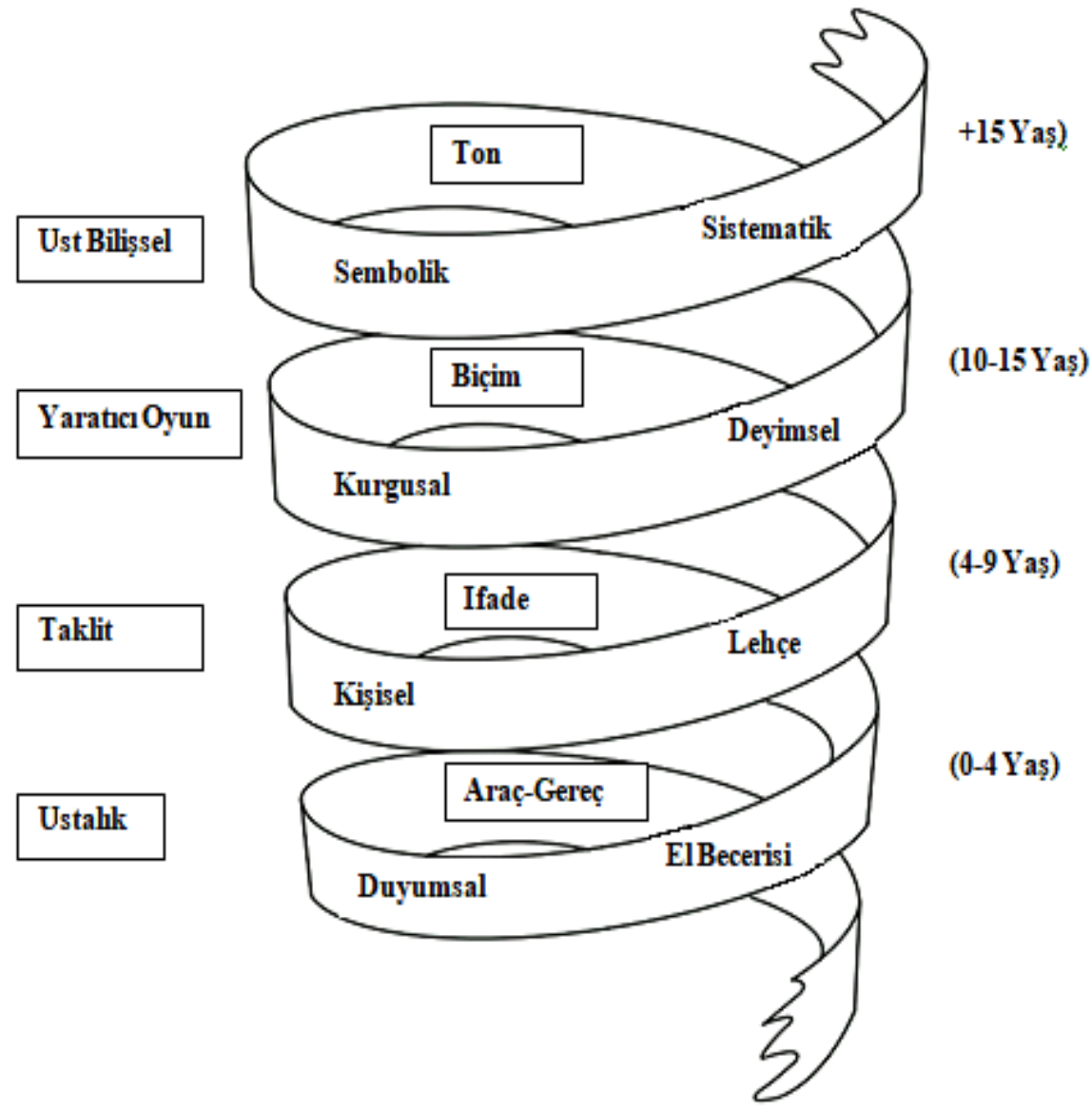

Sosyal Paylaşımlara Doğru

Yapılan araştırmalar incelendiğinde, müziksel yaratıcılığın önemi ve geliştirilmesine yönelik pek çok çalışma yapıldığ görülmektedir. Bu çalışmaların özellikle besteleme ve doğaçlama uygulamalar üzerine yoğunlaştığı görülmektedir. Beste yapmak; müziksel geniş̧lik (müziksel fikirler veya yeni müziksel fikirler), müziksel esneklik (tempo, müziksel dinamik ve müziksel parametrelerin içinde hareket kabiliyeti) ve özgünlük (yeni ve benzersiz müziksel ifadeler) ile yakından ilişkilidir (Webster, 1988). Müziksel yaratıcılığın, özellikle erken çocukluk döneminden itibaren gelişmekte olduğu düşünülürse, müziksel yaratıcılık ile ilgili çalışmaların erken yaşlarda başlatılması ve ilerleyen yaşlarda da sürdürülmesi oldukça önem arz etmektedir (Küpana, 2013; Malkoç, 2014). Müzik

Turkish Studies - Educational Sciences

Volume 14 Issue 3, 2019 
öğretmenlerinin asıl amacı öğrencileri yaratıcı olmak üzerine odaklamak yerine, onların müzikte yaratıcı düşünebilme yeteneklerini geliştirmeleri gerekmektedir (Hickey \& Webster, 2001). Müziksel yaratıcıllğı geliştirmeye yönelik ülkemiz müzik programı incelendiğinde, besteleme ile ilgili kazanımlara da yer verildiği görülmektedir. "Kendi oluşturduğu ezgileri seslendirir" kazanımı doğrudan besteleme ile ilgili olup, öğrencilerin üst düzey düşünme becerilerini de kullanmalarını sağlamaktadır (MEB, 2007).

Hickey \& Webster (2001) çalışmasında, hepimizin yaratıcı düşünme, hareket etme ve yaşama yeteneği ile dünyaya geldiğimizi vurgulamıştır. Bu çalışmada, Webster modelinin de temelini oluşturan Graham Wallas tarafından tasarlanan dört aşamalı yaratıcı düşünme sürecini kullanmıştır. $\mathrm{Bu}$ aşamaları; hazırlık, kuluçka, aydınlanma ve doğrulama olarak değerlendirmişlerdir (Hickey \& Webster, 2001). Çalışmanın bulgularında, yaratıcılığın kompozisyon(besteleme), doğaçlama, dinleme, hareket/dans ve performans gibi müziksel faaliyetlerle ortaya çıkabileceği üzerinde durulmuştur. Çalışmada vurgulanan önemli bulgulardan biri de kişinin müzik öğretimi felsefesinin temel ilkesinin; yaratıcı düşünceyi sesle geliştirmek olması gerekliliğidir.

Crow (2006) çalışmasında, yeni teknoloji ve yaratıcılık temalı çalışmasında İngiltere'deki müzik öğretim programlarının nasıl bir süreçten geçtiği ve besteleme konusunun programlarda yer almaya başlaması ile ilgili ayrıntılı bilgilere yer vermiştir. Çalışmaya göre müzikte yaratıcılık kavramı, ilk defa 1992 yılında müzik eğitim programlarında yerini almaya başlamıştır. 1992 yılından önce müzik öğretim programları performans ve dinleme odaklı iken bu tarihten sonra, 5-14 yaş arası çocukların genel müzik eğitimi için besteleme (kompozisyon), programlara dahil edilmiştir. Müzik derslerinde besteleme konusu şu anda ortaokul müfredatının merkezinde yer almaktadır. Bu çalışma, öğretmenlerin, genel müzik eğitiminde müziksel yaratıcılığa tutarlı yaklaşımlar geliştirmede zorlandıklarını, bununla beraber de gelişen yeni teknolojiyi amaca uygun kullanmaya yönelik bilgi ve beceriyi henüz kavrayamadıklarını ileri sürmüştür. $\mathrm{Bu}$ nedenle müzik müfredatının, yeniden tasarlanması, geliştirilmesi ve kaynak oluşturması gerektiğinin de altı çizilmiştir. Bu programlar yeniden tasarlanırken; müzik eğitimine yönelik mevcut yaklaşımlarımızda var olan varsayımlara değinmek, yaratıcılık anlamını gözden geçirmek, teknolojinin rolünü yeniden değerlendirmek ve bazı öğrencilerin okul müziği içinde sahip oldukları rahatsızlıkları da değerlendirmek gerektiği vurgulanmıştır. Çalışma, hazırlanacak olan müfredatın: Britanya Adaları'ndan müzik, "Batı klasik" geleneği, halk, caz ve popüler türler ile tanınmış bestecilerden oluşan farklı zaman ve kültürlerden canlı veya kaydedilmiş müzikleri içermesi gerektiğini de belirtmiştir. Crow (2006)'a göre müzik eğitiminin amacı müziği daha yararlı, sürdürülebilir ve öğrenciler için değerli bir uğraş haline getirmektir. Bu süreçte de öğretmenler, öğrencilerin yaratıcı fikirlerini teşvik etmeli, geliştirmeli ve değerlendirmeyi doğru bir şekilde yapmalıdır. Çalışmada altı çizilen diğer bir nokta ise, yeni müzik teknolojilerinin, sınıfta yaratıcılığı teşvik ederken ortaya çıkabilecek tüm sorunlara cevap veremeyebileceğidir.

Rozman (2009), Slovenya'daki ilkokullarda, müziksel yaratıcılığı, gözlemlenebilir özellikleri ve bazı benzerlikleri bakımından, öğrencilerin ve öğretmenlerin yaptığı açıklamalar doğrultusunda araştırmıştır. Çalışma, öğrencilerin ve öğretmenlerin sınıfta yaratıcı müzik etkinliklerinden memnun olduklarını, ancak yaratıcı müzikal düşüncenin tüm yönlerini ve müzikal yaratıcılığın değerlendirilmesinin ölçütlerini bilmediklerini göstermiştir. Bulgular, öğretmenlerin müziksel kompozisyon(besteleme) ve doğaçlama öğretme stratejilerini tam olarak bilmediklerini göstermektedir. Önemli bulgulardan bir diğeri ise, üniversitelerin görevinin yaratıcı müzik aktivitelerini uygun bir şekilde sağlayabilecek öğretmenler yetiştirmek ve uygulamalı eğitimleri sırasında öğretmen adayları için benzer içerikli seminerler düzenlemek olduğudur.

Kiehn (2003), 2. 4. ve 6. sınıftan rastlantısal olarak seçtiği 89 öğrencinin müziksel doğaçlama yaratıcılık seviyesini belirlemek amacıyla Vaughan'ın "Müziksel Yaratıcılık Testi” ve Torrance'ın "Yaratıcı Düşünme Testini” kullanmıştır. Araştırma sonucunda müziksel yaratıcılık puanları için 
önemli bir sınıf düzeyi farkı ortaya çıkmıştır. 2. sınıf öğrencilerinin yaratıcılık düzeyleri, 4. ve 6. sınıf öğrencilerden anlamlı olarak daha düşük olduğu sonucuna varılmıştır. Araştırmacı, 2. sınıf ile 4. sınıf arasındaki süreçte yaratıcılığın gelişimi açısından anlamlı bir fark olduğunun altını çizerken, yapılan testler sonucunda 4. ve 6. sınıf öğrencilerinin arasında yaratıcılık gelişimi açısından anlamlı bir fark olmadığını vurgulamaktadır. Ayrıca çalışmanın sonuçları cinsiyet bakımından da değerlendirilmiş ve erkeklerin yaratıcılık düzeylerinin kızlara oranla daha yüksek olduğu belirtilmiştir. Bu sonucun da Baltzer (1991), Webster (1979), Schmidt \& Sinor (1986)'un bulguları ile paralellik gösterdiğini vurgulamaktadir.

Burnard (2000), öğrencilerde doğaçlama ve besteleme sürecinin nasıl gerçekleştiğini, doğaçlama ile besteleme arasındaki ilişkinin doğasını öğrencilerin bakış açısından incelemiştir. Çalışma, yaşları on iki olan 12 kız ve 6 erkeğin oluşturduğu toplam 18 kişilik gönüllü katılımcı ile 21 hafta sürmüştür. Öğrencilerin on dördüne çalg1 dersleri verilmiş, kalan dört öğrenciye ise formal bir çalgı eğitimi verilmemiştir. Çalışmanın sonunda 116 doğaçlama performans ve 79 beste elde edilmiş ve daha sonra değerlendirmeler yapılmıştır. Çocukların bakış açısına göre, besteleme ve doğaçlama; farklı ve ayrı, birbiriyle ilişkili ve ayırt edilemez şeklinde ifade edilmiştir. Çalışma, besteleme ve doğaçlama arasındaki ilişkinin öğrenciler tarafından çeşitli şekillerde tanımlandığını göstermiştir. Çocukların doğaçlama yapma ve bestelemeye yönelik istekliliği, çocukların yaratıcılıklarını ifade edebilecekleri bir ortam yaratılması bakımından oldukça önemlidir. Bu amaçla çalışmada, müzik eğitimcilerine yönelik önerilere de yer verilmiştir. Müzik öğretmenlerinin en önemli görevlerinin, çocukları eleştirel ve yaratıcı düşünmeye teşvik etmek ve desteklemek olduğudur. Müzik derslerinin asıl amacının öğrencilere; kendi müziksel deneyimlerinin özünde ne olduğunu tartışmak, kendilerini sadece müzik yapımcıları olarak değil, müzik yaratıcıları olarak tanımlamak ve doğaçlama ile bestelemenin ne olduğu üzerine düşünmeye teşvik etmek olduğu önemle vurgulanmıştır.

\section{Müziksel Yaratıcılığın Ölçülmesi ve Değerlendirilmesi}

Müziksel yaratıc1lığın değerlendirilmesi, uzun yıllar boyunca müzik dünyasında önemli bir tartışma konusu olmuştur. Araştırmacılar, farklı yaş düzeylerindeki öğrenciler için müziksel yaratıcılığı ölçmek amacı ile çeşitli çalışmalar (Vaughan,1971; Gorder, 1976; Webster, 1979; Webster,1983; Hickey,1999) yapmışlardır.

Vaughan \& Myers (1971), dördüncü ve beşinci sınıf öğrencilerinin müziksel yaratıcılığını değerlendirmek amacıyla Torrence'in Yaratıcı Düşünme Testine (TTCT) dayalı bir "Müzik Yaratıcılık Testi” geliştirmiştir. Gorder (1976) ve Webster (1979) ise ortaokul ve lise öğrencilerinin müziksel yaratıcılık özelliklerini belirlemek amacıyla bazı testler geliștirmiștir. Buna ek olarak Webster (1979) müzik yeteneğinin dokuz yaş civarında sabitlendiği göz önüne alarak, bazı ilk müzikal deneyimleri değerlendirmek amacıyla erken yaşlara yönelik müziksel yaratıcılık ölçme araçlarının gerekli olduğunu öne sürmüştür. Webster (1987)'da "Müzikte Yaratıcı Düşüncenin Ölçülmesi (MCTM)" isimli çalışmasını, çocuklarda müziksel düşünce ve yaratıcılığın erken yaşlardan itibaren başladığını ve bu yüzden müziksel yaratıcılığın 6-10 yaş arasında ölçülebileceği düşüncesinden yola çıkarak yapmıştır. MCTM'nin geliştirilmesinden önce, müziksel yaratıcıllğı ölçmek üzere benzer çalışmalar yapılmış fakat bu çalışmalar daha büyük yaş grupları ile sınırlı kalmıştır. MCTM, kağıt kalem gibi klasik yöntemleri içeren bir ölçek olmaktan çok, bire-bir karşılıklı verilmesi gereken cevapları içeren, zorluk derecesi aşamalı bir şekilde artan ve yapılandırılmış 10 görev dizisinden oluşmaktadır. $\mathrm{Bu}$ nedenle grupla uygulanabilecek pratik bir ölçek değildir. Bu ölçeğin amacı, yaratıcı ürünlerin etkileyicilik ve üretkenlik düzeylerini değerlendirmektir. Ölçek, doğaçlama ve yarı-doğaçlama tekniği ile basit çalgılar kullanılarak uygulanmaktadır.

Müzikte Yaratıcı Düşünme Ölçeği (MCTM), 6-10 yaş arasındaki çocukların müzikte yaratıcı düşünme becerisini ölçmek amacıyla Peter R. Webster tarafindan geliştirilmiş bir ölçektir. Ölçek, zorluk dereceleri aşamalı olarak artan 10 görev dizisinden oluşmaktadır. Ölçeği uygulamak için (1) yuvarlak bir sünger top, (2) bir mikrofon ve (3) beş tınlayıcı tahta blok kullanılır. Tüm aktiviteler, 
sadece çocuğun ve uygulayıcının olduğu özel bir odada, oyun-vari bir atmosfer oluşturularak, ortalama 20-25 dakika süresince gerçekleşir. Görevlerin hepsi fark ettirilmeyecek şekilde video kaydına alınır ve daha sonra değerlendirilir. Kaydedilen videolar, etken müziksel ifadeleri anlayabilecek ve tanımlayabilecek bir uzman tarafından müzikal genişlik, müzikal esneklik, müzikal orijinallik ve müzikal söz dizim alt boyutlarına göre değerlendirilir (Webster, 1994). MCTM'nin orijinal geçerlik güvenirlik çalışmaları, çeşitli araştırmalarda elde edilen bulgular bir araya getirilerek tamamlanmıştır (Webster 1987, 1988, 1990; Swanner, 1985).

Harris \& Hawksley (1989) çalışmalarında, besteleri değerlendirirken gerekli olan ölçütlerin oluşturulması ve değerlendirmenin gerçekleştirilmesinin önemi üzerine çalışma yapmışlardır. Bestelerin değerlendirmesinde aşağıdaki ölçütlerin esas alınması gerektiği üzerinde durulmuştur. $\mathrm{Bu}$ ölçütler; tarzın kurulması ve sürdürülmesi, müziksel ifadelerin geliştirilmesi, farklı çalgıların/ses kaynağının ya da kaynaklarının etkili kullanılması; kontrast (zıtlık) veya paralellik yoluyla ritmik, tonal, melodik ve armonik yönlerin kontrolü, armonik yoğunluğun kontrolü, aralıkların ters veya paralel yönde kullanılması, net performans talimatları, beceriklilik ve özgünlük bir bütün olarak kompozisyonun etkinliği ve akıcılığı, öz eleştiri gücü ve betimlemedir. Araştırmacılar bu ölçütler yoluyla öğrencilerin, kompozisyonlarını (bestelerini) değerlendirildikten sonra bestelerini nasıl geliştireceklerini ve ne yapmaları gerektiğini bilmeleri bakımından bu ölçütlerin önemli olduğunu vurgulamışlardır.

Swanwick \& Tilmann (1986), 4 y1llık süre boyunca sayıları 3 ila 11 yaş arasında değişen toplam 48 çocuğun, verili bir dizi besteleme görev aşamasından oluşturdukları 700'ün üzerinde besteyi analiz ederek gerçekleştirdikleri araştırma sonucunda, müziksel yaratıcılığın gelişimini belirli aşamalara ayırmışlardır (Auh, 1995:22; Kaschub, 1999:59; Swanwick \&Tillman, 1986). Görevler basitten karmaşığa olacak şekilde, bir model oluşturmak, bir parça oluşturmak, bir müzik yapmak, bir çalg1 çalarak şark1 söylemek (örnek şarkılar, cümleler/sözler verildi) veya çocuğun kendi ürettiği bir şarkıyı söylemeyi içeriyordu. Çocuklardan yaptıkları besteleri çeşitli çalgılar üzerinde çalmaları ve ürünlerinden memnun olana kadar çalışmalarına izin verildi. Çocuklar tarafindan oluşturulan bestelerin analizi, çocukların müziksel gelişiminin sarmal bir modelinin oluşturulmasına yol açmıştır. Swanwick \& Tillman, çocukların doğumdan sonraki 4 yıl içerisinde müziğe hakim olmaya başladıklarını, 4 ila 9 yaşları arasında taklit yoluyla öğrendiklerini, 10 ila 15 yaşları arasında hayali oyunlar ile öğrendiklerini ve 15 yaştan sonra üst bilişsel yollarla öğrendiklerini öne sürmüşlerdir. Buna ek olarak, bu dört aşamadan her biri materyallere (tını), ifadeye (nüans), forma (yapıya) ve değere (anlam) ilgi olarak bölünmüştür (Kaschub, 1999). Özellikle 15 yaş ve sonrasında daha olgun bir müzik tarzı geliştirmeye yönelik güçlü bir eğilim fark edilir. Müzikten etkilenme daha belirgindir. Çocuğun bilinç düzeyinin anlatımı ile birlikte müziksel bilişsel süreçler de kendini göstermeye başlar. Bireyler kendi müziksel birikimini yansıtabilecek düzeye erişmiş, donanımlı müzik insanıdır. Estetik kaygıları da gözeterek çok yönlü, imgesel ve orijinal müziksel düşünce yaratmaya başlar. Besteleri bilinçli şekilde oluşturulmuş müziksel materyalleri de içerir (Kaschub, 1999; Swanwick \& Tillman, 1986).

Wilson \& Wales (1995) çalışmalarında, 7 ve 9 yaşındaki çocukların yarattıkları müzikleri (besteleri) ritmik ve melodik açıdan incelemişlerdir. Çalışmada her yaş grubu için 20 öğrenci olmak üzere toplam 40 öğrenci belirlenmiştir. Veri toplamak için "MusicWorks" yazılım programı yardımı ile veriler toplanmış ve çocuklara çalışma süreleri konusunda kısıtlamalar uygulanmamıştır. Uygulamanın sonunda yaratılan besteler uzmanlar tarafından değerlendirildi ve bu değerlendirmeler sonucunda "çalışma grubunun bestelerinde genel olarak batı kültürüne özgü müziği daha yakından andıran tonal ve metrik bir ses sistemi kullandıkları belirlenmiştir. Araştırmacılar, daha yüksek ritmik ve melodik gelişimin kültürlenmenin bir sonucu olduğu ve karmaşı ritim kalıplarının yaş ve müzik eğitimi ilerledikçe arttığını vurgulamaktadır. Bu bulgular, içsel işitme ve müziksel hafızanın kompozisyon becerilerinin gelişiminde anahtar rol oynadığını göstermektedir. 
Trinity College London, diploma düzeyinde müziksel kompozisyon (besteleme) ve okuryazarlığ 1 için farklı bir değerlendirme ölçütü kullanmaktadır. Trinity Koleji'nin müziksel kompozisyon değerlendirmesi; teknik, iletişim, müziksel anlam ve müziksel uyum olmak üzere toplam dört ölçütden oluşmaktadır. Teknik yapı: kompozisyon ve teorik tekniklerin kontrolü, çalgıların doğru seçimi ve notasyonun doğru kullanımını içerir. İletişim aşaması: sunumun açıklığı ve amacı, üretilen ses dokusunun genel kalitesi ve amaca yönelik olmasından oluşmaktadır. Müziksel anlam, müzik tarzının bilinçli bir şekilde seçilmesi, yapılan çalışmanın seçilen tarz ile uyumlu ve karakteristik müziksel ifadeleri içermesidir. Bütünleştirme (entegrasyon); uyum, doğallık, özgünlük ve yaratıcılık içeren bir işi üretmek ve sunmak için gerekli olan bilgi, beceri ve farkındalığı bütünleştirme konusundaki bütünsel yeteneği vurgular (Trinity College London, 2019).

\section{Müziksel Kompozisyonlar Üzerinden Müziksel Yaratıcılığı Değerlendirmeyi Sağlayan Bir Ölçme Aracı Olarak Rubrikler}

Son yıllarda her alanda olduğu gibi eğitim ve öğretim alanlarında da yeniliklerin hızla arttı̆̆ görülmektedir. Özellikle öğretmen odaklı öğretim programları yerine daha çok öğrenen ve süreç odaklı programlar kullanılmaya başlanmıştır. Programlarda yaşanan bu gelişmelere paralel olarak ölçme ve değerlendirme yöntemlerinde de değişiklikler meydana gelmiştir. Daha önce yaygın bir şekilde kullanılan ürün odaklı değerlendirme yöntemleri, yerlerini hızla süreç ve performans odaklı değerlendirmeye bırakmıştır (Abalı, Öztürk \& Şahin, 2014). Performans odaklı değerlendirme yöntemlerinde, öğrencilerin bilişsel, duyuşsal, psikomotor ve sosyal becerileri farklı boyutları ile ele alınmakta ve incelenmektedir. Performans odaklı değerlendirme yöntemi; klasik ölçme araçları ile ölçülemeyen öğrenme hedef ve davranışların ölçülmesine, öğrenmelerin kalıcılığının arttırılmasına, öğrencilerin motivasyonlarının arttırılmasına ve öğretmenlerin ölçme sürecinde daha aktif olmalarına katk1 ve kolaylık sağlamaktadır (Abalı Öztürk \& Şahin, 2014; Birel \& Albuz, 2014; Öztürk \& Güdek, 2016).

Müzik, resim, spor gibi yetenek ve beceri gerektiren alanların değerlendirme süreçleri daha çok performansa dayalı olduğundan subjektif (öznel) olmaktadır. Rubrik, bu gibi performansa dayalı alanların değerlendirilmesinde öğretmenlere ve araştırmacılara kolaylık sağlamaktadır. Rubrik: daha çok subjektif ve otantik değerlendirmeler için kullanılan, önceden yapılandırılmış performans görevleri üzerinde farklı düzeylerde performansa yönelik belirli özellikleri ve ölçütleri tanımlayan ve bu özellikler doğrultusunda performansa ya da ürüne ilişkin yargıya varmada kullanılan puanlama rehberi/cetveli olarak tanımlanabilir (Birel \& Albuz, 2014; Kan, 2007; Tierney, \& Simon, 2004; ). Rubrik, değerlendirilecek alan için en iyiden kötüye doğru önceden belirlenen esaslar göz önünde bulundurularak derecelendirilir (Birel \& Albuz, 2014; Öztürk \& Güdek, 2016; Popham 1997). Rubrikler kullanım amaçlarına göre Holistik ve Analitik olmaz üzere iki gruba ayrılır.

1. Holistik Rubrik: Daha çok sanatsal çalışmaların değerlendirilmesinde kullanılan bu rubrik türünde tamamlanmış bir performans ya da ürünün tamamına bakılarak değerlendirme yapilir.

2. Analitik Rubrik: Herhangi bir performans ya da ürünün parçalara bölünerek değerlendirildiği türdür. Bu rubrik türünün asıl amac1, ölçmek istediğimiz bir yetenek boyutunu öğelerine ayrıştırarak daha ayrıntılı bir puanlama yapabilmektir (Birel \& Albuz, 2014; Kan, 2007).

Son yıllarda yapılan araştırmalarda, müziksel yaratıcılığın değerlendirilmesinde genellikle rubrik ve benzeri araçların kullanıldığı, müziksel yaratıcılığın da alanlarında uzman kişiler tarafından değerlendirildiği görülmektedir. Alternatif değerlendirme aracı olan rubriklerin başarılı bir şekilde kullanıldığı ve yaygınlaştırılması gerektiği birçok çalışmada vurgulanmaktadır (Hickey, 1999; Ryan \& Brown, 2012; Scott, 2012; Deluca \& Bolden, 2014). 
Webster (1987a, 1987b, 1987c) çalışmalarında müziksel kompozisyonlarını değerlendirmek amacıyla dört ölçüt belirlemiştir. Bu ölçütler; müziksel sözdizim, müziksel genişlik, müziksel esneklik ve müziksel özgünlüktür. Benzer şekilde Hickey, (1990) "Müzik Besteleri İçin Değerlendirme Rubrikleri" isimli çalışmasında bu değerlendirme aracı için; öğretmenler ve öğrenciler kompozisyon (besteleme) ödevleri için değerlendirme listeleri geliştirmek için birlikte çalışabilirler. Ayrıca, değerlendirme araçlarını öğrencileri cezalandırmak için değil onları eğitmek ve geri bildirimlerde bulunabilmek amacıyla kullanmak gerektiğini vurgulamıştır. Harris \& Hawksley'in (1989) müzik kompozisyonlarını değerlendirmek için geliştirdikleri ölçme aracında bazı ölçütler belirlemişlerdir;

- Ritmik, tonal, melodik, harmonik yönler ve doku yoğunluğunun kontrolü,

- Çalgıların, seslerin veya diğer ses kaynaklarının etkili ve doğru kullanımı,

- Müziksel düşüncenin (fikrin) geliştirilmesi, aralıklar arasındaki zıtlık ve ya uyum,

- Kompozisyonun (bestenin) bir bütün olarak etkinliği ve akıcıllı̆ı,

- Müzik tarzının belirlenmesi ve sürdürülmesi,

- Özgün bir eser yaratma becerisi,

- Kendini ifade edebilme ve tanımlaya bilme becerisi.

Londra Uluslararası Trinity Koleji Sınav Kurulu'nun besteleme için geliştirdiği ölçme aracı da rubrik şekline olup, değerlendirmeler bazı ölçütlere göre yapılmaktadır. Bu ölçütler; kullanılan ses dokusunun genel kalitesini içeren teknikler, cümleler ve müziksel karakter, orkestrasyon için uygun ve doğru enstruman seçimi ve kalitesi, doğru ve açık notasyon kullanımı, besteleme ve teorik tekniklerin kontrolü, bütünsel ifadeler, müziksel uyum ve kendi tarzını oluşturma, yaratıcılık, bireysellik ve kişisel çaba, müziksel bağlam ve amaca uygunluktur (Trinity College London, 2019).

\section{Sonuc}

Alan yazın incelendiğinde yaratıcılık ve müziksel yaratıcılığın son yıllarda üzerine oldukça fazla sayıda araştırma yapılan birer kavram olduğu ortaya çıkmıştır. Yapılan çalışmaların, yaratıcılığı tanımlamak, ölçümlemek, geliştirmek ve değerlendirmek üzerine yoğunlaştığı görülmüştür.

Yaratıcılı̆̆g tanımlamak üzerine yapılan çalışmalar (Csikszentmihalyi, 1999; Gardner, 2011; Guilford, 1950; Kurtzberg \& Amabile, 2001; Torrance'nin, 1962; 1966; 1974; Sternberg, 2006) incelendiğinde genel bir ifadeyle yaratıcılık, yeni ve uygun bir ürün ortaya koymak olarak tanımlanmaktadır. Bu tanımın yanı sıra yaratıcılığın, entelektüel beceriler, bilgi, düşünme stilleri, kişilik, motivasyon ve çevre değişkenlerinden oluştuğu ortaya konmuştur (Sternberg \& Lubart, 1991; 1995). Aynı zamanda yaratıcılığın akıcılık, esneklik, yenilik, sentez, analiz, yeniden düzenleme, yeniden tanımlama, karmaşıklık ve detaylandırma yapılarını içerdiği ortaya konmuştur (Kurtzberg \& Amabile, 2001).

Yine birçok araştırmacı (Elliott, 1989; Hickey \& Webster, 2001; Piji,2003; Swanwick \& Tilmann,1986; Webster, 1988; 2002) tarafından tanımlanmaya çalışılan ve yaratıcılığın bir dalı olarak görülen müziksel yaratıcılığın ise müziksel anlamda yeni bir fikir, düşünce veya ürün ortaya koymak olarak ifade edilmektedir. Müziksel anlamda yaratıcı ürün ortaya koyma sürecinde, kişinin öncelikle bir amac1 olduğu, bu amaç doğrultusunda geliştirdiği kompozisyon, performans ve analiz sürecinde düşünme becerilerini kullandığı görülmektedir. Iraksak düşünme sürecinde becerileri etkinleştirme, yatkınlık ve olanaklar doğrultusunda yaratıcı ürün ortaya koyma, hazırlık, kuluçka, aydınlanma ve ispat süreçlerinden oluşmaktadır. Yakınsak düşünce sürecinde ise estetik hassasiyet, kavramsal anlayış ve ustalık değişkenleri doğrultusunda yine aynı yaratıcı ürün koyma süreci gerçekleşmektedir. Bu süreçler tamamen birbiriyle etkileşim halindedir. Bu süreçlerin sonunda yaratıcı ürün bir kompozisyon (beste, eser), performans veya analiz olarak ortaya çıkmaktadır. Aynı zamanda, müziksel yaratıcılığın 
gelişmesinde, müziksel gelişimin önemli bir etken olduğu görülmüştür. Bu gelişimin bilişsel gelişimle paralel olarak yaşamın ilk yıllarında duyusal, ilerleyen yıllarda ise sırasıyla taklit, oyun ve üst bilişsel yolla öğrenme şeklinde gerçekleştiği görülmüş̧ür.

Müziksel yaratıcılığın ölçümlenmesi ve değerlendirilmesi amacıyla yapılan yoğun araştırmalar incelendiğinde, Torrance'ın Yaratıcı Düşünme Testinden yola çıkılarak Müzikte Yaratıcı Düşünme Testlerinin üretildiği görülmektedir. Bu testler daha çok performansa yönelik değerlendirme süreci olarak tasarlanmıştır. Müzikte yaratıcı düşünceyi sonuç odaklı değerlendirmekten ziyade, sürece dayalı değerlendirme yöntemlerinin tercih edilmesiyle birlikte "Holistik Rubriklerin" kullanılmaya başlandığı görülmüştür. Bu değerlendirme yönteminin de müziksel yaratıcılığı ölçümlemede, hedef ve davranışların ölçülmesi, öğrenmelerin kalıcılığının arttırılması, öğrenci motivasyonunun arttırılması ve eğitimcilerin ölçme sürecinin içinde ve aktif olması konularında katkı sağladığı görülmektedir.

\section{KAYNAKÇA}

Amabile, T. M. (1983). The social psychology of creativity. New York: Springer.

Auh, M. S. (1995). Prediction of Musical Creativity in Composition Among Selected Variables for Upper Elementary Students. Yayınlanmamış Doktora Tezi, Ohio Üniversitesi.

Baltzer, S. W. (1991). A Factor Analytic Study of Musical Creativity in Children in the Primary Grades. Yayınlanmamış Doktora Tezi, Indiana Üniversitesi.

Birel, A. S., \& Albuz, A. (2014). Viyolonsel öğretiminde performansı değerlendirmeye yönelik hazırlanan dereceli puanlama anahtarının (rubrik) sınanması ve değerlendirilmesi. Atatürk Üniversitesi Sosyal Bilimler Enstitüsü Dergisi, 18(3).

Burnard, P. (2000). Examining experiential differences between improvisation and composition in children's music-making. British journal of music education, 17(3), 227-245.

Burnard, P. (2007). Routes to Understanding Musical Creativity. In International Handbook of Research in arts Education (pp. 1199-1224). Springer, Dordrecht.

Craft, A., Gardner, H., \& Claxton, G. (Eds.). (2007). Creativity, Wisdom, and Trusteeship: Exploring the Role of Education. Corwin Press.

Crow, B. (2006). Musical creativity and the new technology. Music Education Research, 8(1), 121130.

Csikszentmihalyi, M. (1999). 16 Implications of A Systems Perspective for The Study of Creativity. In Handbook of creativity (ss. 313-335). Cambridge University Press.

Csikszentmihalyi, M. (2014). Society, Culture, and Person: A Systems View of Creativity. In The Systems Model of Creativity (ss. 47-61). Springer, Dordrecht.

Davaslıgil, Ü. (1989). Yaratıcılık ve Oyun. Eğitim ve Bilim, 13(71).

Deluca, C., \& Bolden, B. (2014). Music performance assessment: exploring three approaches for quality rubric construction. Music Educators Journal, 101(1), 70-76.

Elliott, D. J. (1989). The Concept of Creativity: Implications for Music Education.

Gardner, H. (2011). Frames of mind: The theory of multiple intelligences. Hachette UK.

Gorder, W.D. (1976). An Investigation of Divergent Production Abilities as Constructs of Musical Creativity. Yayınlanmamış Doktora Tezi, Illinois Üniversitesi

Guilford, J. P. (1950). Creativity. American Psychologist, 5, 444-454. 
Harris, R., \& Hawksley, E. (1989). Composing in the Classroom. Cambridge University Press.

Hickey, M. (1999). Assessment rubrics for music composition: rubrics make evaluations concrete and objective, while providing students with detailed feedback and the skills to become sensitive music critics. Music educators journal, 85(4), 26-52.

Hickey, M., \& Webster, P. (2001). Creative thinking in music. Music Educators Journal, 88(1), 19-23.

Kan, A. (2007). Performans değerlendirme sürecine katkıları açısından yeni program anlayışı içerisinde kullanılabilecek bir değerlendirme yaklaşımı: Rubrik puanlama yönergeleri. Kuram ve Uygulamada Eğitim Bilimleri, 7(1), 129-152.

Kaschub, M. E. (1999). Sixth grade student's descriptions of their individual and collaborative music composition processes and products initiated from prompted and umprompted task structures. Yayınlanmamış Doktora Tezi, Northwestern Üniversitesi.

Kiehn, M. T. (2003). Development of music creativity among elementary school students. Journal of research in Music Education, 51(4), 278-288.

Kurtzberg, T. R., \& Amabile, T. M. (2001). From Guilford to creative synergy: Opening the black box of team-level creativity. Creativity Research Journal, 13(3-4), 285-294.

Küpana, M. N. (2013). Müzikal yaratıcılı̆̆ geliştiren yaklaşımlar. Eğitim ve Öğretim Araştırmaları Dergisi Journal of Research in Education and Teaching, 2 (2).

Mazzola, G., Park, J., \& Thalmann, F. (2011). Musical Creativity: Strategies and Tools in Composition and Improvisation. Springer Science \& Business Media.

M.E.B. (2007). Bilim ve Sanat Merkezleri Yönergesi. Online: http://mevzuat.meb.gov.tr.

Özkişi, Z. G. (2013). Contemporary Music from Turkey: Turkish composer Özkan Manav's approaches to the local materials in. Turkish Studies International Academic Journals, 8(9), 2069-2091.

Öztürk, D., \& Güdek, B. (2016). Viyolonsel performans değerlendirmesine yönelik dereceli puanlama anahtarının (rubrik) geliştirilmesi. Afyon Kocatepe Üniversitesi Akademik Müzik Araştırmaları Dergisi, 2(3), 31-50.

Popham, W. J. (1997). What's Wrong-and What's Right-With Rubrics. Educational Leadership, 55, $72-75$.

Rawat, K. J., Qazi, W., \& Hamid, S. (2012). Creativity and Education. Academic Research International, 2(2), 264.

Rozman, J. Č. (2009). Musical Creativity in Slovenian Elementary Schools. Educational research, 51(1), 61-76.

Runco, M. A. (2008). Creativity and Education. New Horizons in Education, 56(1).

Ryan, T. G., \& Brown, K. (2012). Musical creativity: Measures and learning. Journal of Elementary Education, 22(2), 105-120.

Sak, U. (2014). Yaratıcılık Gelişimi ve Geliştirilmesi. Ankara: Vize Yayıncılık.

Sak, U. (2014). Üstün Zekâlılar: Özellikleri Tanılanmaları Eğitimleri. Ankara: Vize Yayınevi.

Schmidt, C. P., \& Sinor, J. (1986). An investigation of the relationships among music audiation, musical creativity, and cognitive style. Journal of Research in Music Education, 34(3), 160172. 
Scott, S. J. (2012). Rethinking the roles of assessment in music education. Music Educators Journal, 98(3), 31-35.

Shaheen, R. (2010). Creativity and Education. Online Submission, 1(3), 166-169.

Sternberg, R. J., \& Lubart, T. I. (1991). An investment theory of creativity and its development. Human Development, 34(1), 1-31.

Sternberg, R. J., \& Lubart, T. I. (1995). Defying the Crowd. New York: Free Press.

Sternberg, R. J., \& Lubart, T. I. (1996). Investing in creativity. American psychologist, 51(7), 677.

Sternberg, R. J. (2006). The nature of creativity. Creativity research journal, 18(1), 87-98.

Swanner, D. L. (1985). Relationships between musical creativity and selected factors, including personality. motivation, musical aptitude, and cognitive intelligence as measured in third grade children. UMI Dissertation Services.

Swanwick, K., \& Tillman, J. (1986). The sequence of musical development: A study of children's composition. British journal of music education, 3(3), 305-339.

Şahin, Ç., \& Öztürk, Y. A. (2014). Sınıf öğretmeni adaylarının alternatif ölçme-değerlendirme yöntemlerine ilișkin görüșleri. Kastamonu Eğitim Dergisi, 22(1), 123-142.

Tierney, R., \& Simon, M. (2004). What's still wrong with rubrics: focusing on the consistency of performance criteria across scale levels. Practical Assessment, Research \& Evaluation, 9(2), $1-10$.

Torrance, E. P. (1962). Guiding creative talent. Englewood Cliffs, NJ: Prentice Hall.

Torrance, E. P. (1966). The Torrance Tests of Creative Thinking-Norms-Technical Manual Research Edition-Verbal Tests, Forms A and B-Figural Tests, Forms A and B. Princeton, NJ: Personnel Press.

Torrance, E. P. (1974). Torrance tests of creative thinking. Lexington. MA: Personnel Press.

Trinity College London (2019). 20.12.2019 tarihinde https://www.trinitycollege.com/adresinden erişildi.

Vaughan, M., \& Myers, R. E. (1971). An examination of musical process as related to creative thinking. Journal of Research in Music Education, 19(3), 337-341.

Wallas, G. (1926). The art of thought. New York: Harcourt Brace.

Wilson, S. J., ve Wales, R. J. (1995). An exploration of children's musical compositions. Journal of Research in Music Education, 43(2), 94-111.

Webster, P.R. (1979). Relationship between creative behavior in music and selected variables as measured in high school students. Journal of Research in Music Education, 27(4), 227-242.

Webster, P.R. (1983). Refinement of A Measure of Musical Imagination in Young Children And a Comparison to Aspects of Musical Aptitude. Paper presented at the Loyola Symposium on Creativity.New Orleans, LA.

Webster, P. R. (1987). Refinement of a Measure of Creative Thinking in Music. Applications of Research in Music Behaviour. C. Madsen\& C. Prickett (Eds.), Tuscaloosa, Alabama: The University of Alabama Press. 
Webster, P. R., Yale, C. \&Haefner, M. (1988). Test-retestreliability of Measures of Creative Thinking in Music Forchildren with Formal Music Training. Poster Session of MENC Conference: Indianapolis.

Webster, P. R. (1990). Study of internalreliabilityfortheMeasure of Creative Thinking in Music. General Poster Session of the MENC National Convention: Washington D.C.

Webster, P. R. (1994). Measure of Creative Thinking in Music (MCTM) Administrative Guidelines.

Webster, P. R. (2002). Creative thinking in music: Advancing a model. creativityandmusic education. T. Sullivan\& L. Willingham (Eds.), Toronto: Canadian Music Educators' Association.

Webster, P. R. (2007). Computer-Based Technology and Music Teaching and Learning: 2000-2005. In International handbook of research in arts education (ss. 1311-1330). Springer, Dordrecht.

Webster, P. R. (2012). Key research in music technology and music teaching and learning. Journal of Music, Technology \& Education, 4(2-3), 115-130. 